\title{
Nexus between Emotional Intelligence (EQ-I) and Entrepreneurial Culture
}

\author{
Jimisiah Jaafar, Halimah Mohd Yusof, Sallaudin Hassan, Khairul Firdaus Adtrudin, Rohaizan \\ Ahmad
}

\begin{abstract}
This paper discussed on the conceptual framework of EQ-I emotional intelligence, relevant emotional intelligence theories, current findings and measuring tools for the research methodology that are highly possible correlated to an entrepreneurial culture. Emotional Intelligence scientists such as Thorndike and Gardner pioneered the path for researchers and experts in emotional intelligence. The Emotional Quotient Inventory (EQ-i) is the primary scientific instrument and approved as an instrument to measure emotional intelligence. The Multi-factor Emotional Intelligence Scale also known as Mayer, Salovey, Caruso Emotional Intelligence Test is a test of efficacy. Emotional Competence Inventory (ECI) Competency Inventory, designed by Richard Boyatzis and Daniel Goleman, which measured emotional intelligence as a set of skills. Emotional Intelligence Mapping (EQ-Map) is another set of emotional intelligence is the scale of the EQ-Map self-report, parallel to EQ-i. The effort to cultivate creative and innovative thinking among entrepreneurs and potential entrepreneurs based on the Plan of Education Development Master Plan (PIPP 2006-2010) and (PIPP 2013-2018) capitalised on human and soft skills with emotional intelligence as the core of positive attitude needs to be nurtured from school.
\end{abstract}

Index Terms: emotional intelligence, . Emotional Intelligence Mapping

\section{INTRODUCTION}

The discussion of this paper is highlighted on the conceptual framework of Bar-On or EQ-I emotional intelligence, relevant emotional intelligence theories, entrepreneurial culture, current findings and measuring tools for research methodology.

The importance of Emotional Intelligence to entrepreneurs likewise discussed at the end of this research. Therefore, emotional intelligence needs to be studied in more depth.

There are various definitions of emotional intelligence that have been defined, including by Mayer and Salovey (1990, 1993, 1997), Goleman (1995, 1998) and Bar-On Reuvan (1997).

\section{A. Definition of Emotional Intelligence by Mayer And Salovey}

John Mayer and Peter Salovey (1990), defined emotional

Revised Manuscript Received on 14 September, 2019. Jimisiah Jaafar, Universiti Kuala Lumpur, Malaysia Halimah Mohd Yusof, Universiti Teklonogi Malaysia Sallaudin Hassan, Universiti Kuala Lumpur, Malaysia Khairul Firdaus Adtrudin, Universiti Kuala Lumpur, Malaysia Rohaizan Ahmad, Universiti Kuala Lumpur, Malaysia intelligence as a person's ability to identify, understand, use and control his emotions. Then, in 1993, the term of emotional intelligence was redefined as part of the intelligence and social skills associated with one's ability to understand his own emotions, the emotions and feelings of others and to distinguish between emotionally. This capability helps an individual to further improve the growth and development of the emotions and intellect (Mayer \& Salovey, 1997).

\section{B. Definition of Emotional Intelligence by Goleman}

Goleman (1995) defined emotional intelligence as one's ability to understand the emotions of oneself while understanding the emotions of others; the ability to manage emotions while self-motivating and the ability to control emotions through relationships with others.

\section{Definition of Emotional Intelligence by Bar-On}

According to Reuven Bar-On, the model of emotional intelligence can be divided into five main components, namely intrapersonal, interpersonal relationships, stress management, self-adaptation and mood. Reuven Bar-On (2000) also defined emotional intelligence as the intelligence of various non-cognitive capabilities, competencies and skills that influence one's ability to succeed in the face of self-sufficiency and environmental pressures.

\section{Definition of Emotional Intelligence by Other Researchers}

Mayer et. al.,(2008) on the other hand defined emotional intelligence as one's ability to manage their emotions more effectively and to think better.

On the contrarily, Murray (1998) highlighted that emotional intelligence is an ability to self-control rather than possess negative emotions such as anger and hesitation.

Therefore, based on previous researchers definitions, it can be highlighted that emotional intelligence are basically related to the capacity of individual capability to understand and control their emotions and the abilty to connect with others' emotions judiciously and empathetically

\section{E. Explanation of the Basic Definition of Emotional Intelligence}

Peter Salovey and John Mayer (1997) were the prominent researchers who first introduced the term emotional intelligence. This is followed by Daniel Goleman (1999) who developed the definition

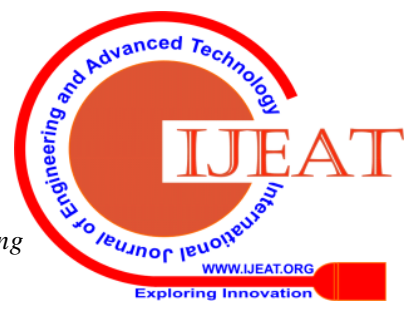


of emotional intelligence.

According to Salovey and Mayer (1990), the characteristics of emotional intelligence are:

1. Ability to know the emotions themselves

2. Ability to manage emotions

3. Self-Improvement Skills

4. Ability to control the emotions of others

5. Ability to establish a brotherhood.

As for Goleman (1998), there are five core dimensions of emotional intelligence. :Self-awareness - self-examination and self-awareness; On the other hand, Thorndike's social intelligence is related to three aspects of understanding and self-management with others, the ability to understand and manage ideas (abstract intelligence), concrete objects (mechanical intelligence), and relationships with others (social intelligence) (Derksen, et al.., 2002: 37-38). Social intelligence includes the ability to understand and manage ideas wisely in establishing a human or adult relationship between men or women (Cantor \& Kihlstrom, 1987).

Prior to that, David Wechsler introduced the Wechsler Adult Intelligence Scale (WAIS) test, which is an intelligence test with two elements, namely non-intellectual elements, including effective, personal, and social factors, and elements of cognitive intelligence. This variety of intelligence has been regarded by Gardner to be as important as the type of common intelligence measured as the I.Q test (Gardner, 1983).

\section{F. Model of Emotional Intelligence}

Early scientists such as Thorndike (1920) and Gardner (1993), pioneered the path for researchers and experts in emotional intelligence. Each theory describes the concept of emotional intelligence based on the paradigm rather than one of the following perspectives:

The ability or capability

Mixed models.

The ability model considers emotional intelligence as a form of pure mental capacity and considered as pure intelligence (Mayer \& Salovey, 1997). This paper will further discuss the potential model of Mayer and Salovey (1997) and both models of emotional intelligence, Reuven Bar-On Emotion Model (1997) and Goleman Emotional Intelligence Model (1998).

Reuven Bar-On (1997) had outlined a mixed model in personality theory, which the model emphasized on the ability of a person to join the personality towards personal well-being. On the contrarily, Daniel Goleman proposed a mixed model, which the focus is in terms of work performance by integrating the ability or ability to work with personalities at work (Goleman, 2001).

\section{G. Salovey and Mayer models: The Model of Emotional Intelligence Ability}

Mayer and Salovey's emotional intelligence concepts were determined by the equivalent or standard criteria. The concepts suggest that emotional intelligence comprises of two areas, namely the ability to experience (to view, react and manipulate emotional information without understanding) and strategic ability (to understand and manage emotions without experiencing full experience or assuming a feeling is good). Emotional perceptions also suggest the ability to express differences between honest and unfair emotions.

Experience in the second branch is emotional assimilation in relation to the ability to differentiate between the feelings the person feels with the feelings identified and whether it affects his thinking process or the development of his emotions.

The strategic capabilities in the third branch are the ability to understand complex emotions (such as feeling two concurrent emotions) and the ability to recognise the transition from one emotion to another.

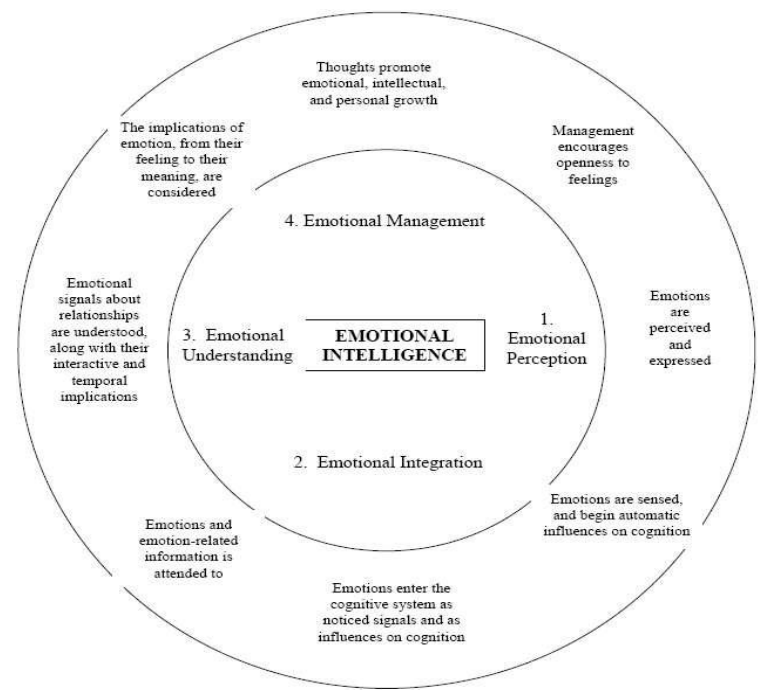

Fig. 1: Model Four Branches of the Emotional Intelligence Network Mayer \& Salovey (1997).

Source: Yvonne Stys and Shelley L. Research Branch Correctional Service of Canada.

\section{H. First Branch: Perception of Assessment and Output of Emotions}

The first branch of emotional intelligence involves one's ability to identify emotions and all that related to it accurately. From there a person can assess his sensitivity towards the expression of pure or false feelings, honest or treacherous by acting to manipulate feelings with certain intentions.

\section{Second Branch: Emotional Use / Emphasise Emotion}

The second branch of emotional intelligence relates to one's understanding of emotion and the stage of his emotional ability to support his thinking. The implication is that one can feel, understand and aware that different states of mind can generate different work.

\section{J. Understanding Emotions and Emphasising Emotional Knowledge in Interpersonal Relationships}

The third branch of emotional intelligence relates to the ability of one to understand emotions and to apply emotional knowledge through emotional signals and relationships between individuals interactively. Understanding the development of feelings in interpersonal relationships with the ability to refine and explain complex emotions is something that is a significant

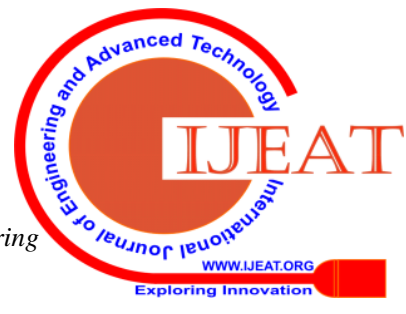


in emotional intelligence.

\section{K. Integration of Emotional Management as Intellectual Developers}

The emotional intelligence branch involves a conscious and subtle emotional handling for the purpose of promoting emotional and intellectual development in an integrated manner. The implication of intellectual is that emotional and personal implications begin with intrapersonal feelings that arises within one's personality until his feelings and behaviour can affect the feelings of others through a two-way interpersonal relationship with a specific purpose.

The ability to monitor or reflect on the emotionally feel can help to alter emotions or regulate the state of the heart. With one's emotional intelligence it is able to foster the spirit and influence others fairly beside being able to work collaboratively with endurance or emotional stamina.

Based on the Bloom hierarchy assessment approach as shown in Figure 2 (Bloom, et al., 1956), the theory proposed by Mayer and Salovey can be accepted as a legitimate concept by many emotional intelligence theory critics as the theory is believed to significantly contribute to the personality of people even from diverse background (Newman, et al., 2010).

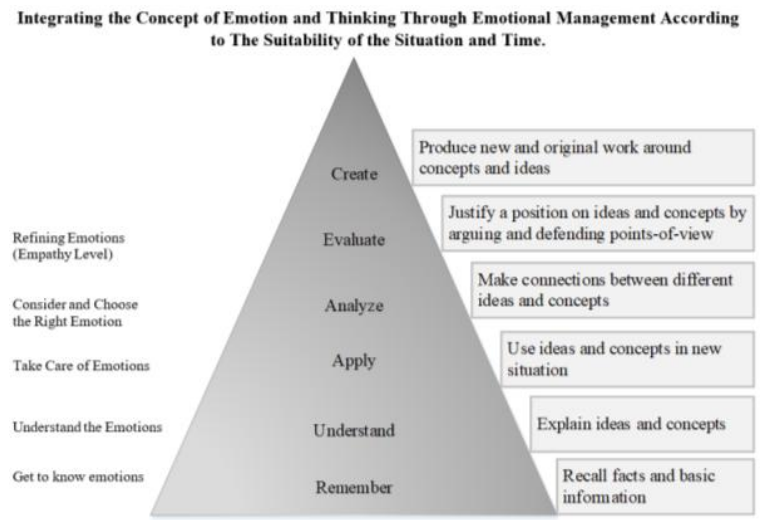

Fig. 2: Rationally Adjusted EQ Mayer \& Salovey (1997) and Bloom Framework

\section{Model of Social-Emotional Intelligence (Bar-On, 1997)}

The Bar-On social-emotional intelligence model can be divided into two basic parts. Both sections of the social-emotional intelligence model are referred to as the Bar-On the social-emotional intelligence model and Bar-On's emotional-social psychometric model by its components. Emotional intelligence is defined as a range of non-cognitive capabilities, competencies and skills that influence one's ability to address environmental pressure and demand (Bar-On, 1997)

Therefore, to fulfil the purpose of this paper, Bar-On or EQ-i emotional intelligence model are the basis or rationale for the discussion:

1. Bar-On's emotional intelligence or emotional factors are in line with the measurement of entrepreneurial status and entrepreneurial characteristics. This includes the measurement of an entrepreneurial culture that refers to successful entrepreneurial attitudes, personality and skills (Yitshaki, 2012).

Table 1: (1997), Bar-On Emotional Quotient Inventory, A Measure of Emotional Intelligence, Multi-Health Systems

Inc, Toronto, On North Tonawanda, NY, pp 1- 1

\begin{tabular}{cccc}
\hline Factor $/$ & Sub-Factor & & \\
Component & $\begin{array}{c}\text { Component } / \\
\text { Sub company }\end{array}$ & Abrr. Definition \\
& &
\end{tabular}

\begin{tabular}{llll}
\hline A.Intrapersonal & Emotional & & Recognise and \\
(IRA) & Awareness & EKK & Understand \\
(Self-Awareness & Emotional & & Self-Emotions \\
and & & & Look closely, \\
Self-Expression) & Self-assessment & PK & understand and
\end{tabular}

Self-Expression) Self-assessment

PK understand and accept yourself Doing self-work and

Self-reliant

BK free from

emotionally

dependent

people.

Construct and

express the

Assertions

AS emotions and

rights of self

constructively

Seeks to

achieve

Self-Esteem

PHK

personal goals

and realise the

potential of a

person

B. Interpersonal

(IRE) (Social

Awareness and

Empathy

Realises and

Interpersonal

Relationships)

Social Response

EM

understands the

feelings of

others

Identify a

person's social

TJS group and

collaborate

with others

Creates a good

relationship

Interpersonal

Relationship

HI that is hooked

and satisfying

with others

Builds and

maintains a

C. Pressure

Management

(PT) Emotional Stress Tolerance

Management

and Control
TS

constructive

and effective

feeling

Build and

control

Impulse Control KIM emotionally constructively and effectively 
D. Adaptation

(KD)

(Change

Problem

Management)

Solution

Flexibility

E. Heartbeat

(SH)

(Regarding Optimise

Self-Motivation)

Cheerfulness
Solve personal

and

PM interpersonal

problems

effectively

Confirms your

thoughts and

PR feelings with

external reality

objectively

Adapting one's

behaviour,

KF feelings and

thoughts in a

new situation.

Element

motivation

OP feels positive

and looks

bright to life

Elements of motivation are

KC satisfied with

yourself, others

and life in

general

1. Bar-On's emotional intelligence model includes the skills in organisational culture with intrapersonal, interpersonal, stress management, self-adaptation and mood states are part of elements of performance in an entrepreneurial organisation (Yvonne \& Shelley, 2004).

2. Based on the definition presented by the researcher, it can be coculded that all the definitions and concepts of Bar-On's emotional intelligence can be referred to as the thoughts, feelings and social relationships behind the actions of an entrepreneur based on the pattern of conduct, feedback, personality in various situations of change and influence of products, services, industry or market.

Table 1 and Figure 3 showcase five components of emotional intelligence and the five dimensions of Bar-On emotional intelligence presented by Dr Reuvan Bar-On through the EQ-I model which was introduced in 1997.

\section{Goleman Intelligence Competence Model (1995, 1998)}

Goleman $(1995,1998)$ stated that EQ is the capacity to identify oneself, motivate

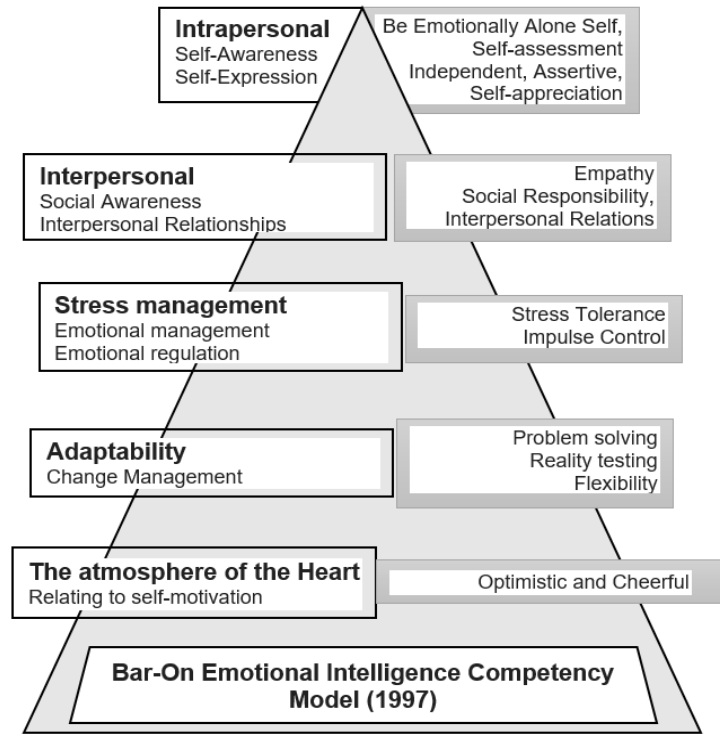

Fig. 3: Components and Dimensions of Bar-On Emotional Intelligence

oneself, empathy towards others and manage emotions effectively with themselves or when communicating with others. There are several EQ capacities proposed:

1) Independent

This capacity explains that every EQ competency will bring uniqueness and goodness to the individual's work performance.

2) Depending on each other

This capacity also explains that each EQ competence has strong interactions and relationships with one another.

3) Hierarchy

In this capacity, EQ competence is seen to interact and relate to each other. Emotional and self-management are important aspects that contribute to the motivation of an employee.

4) Need But Not Enough

This capacity explains that EQ's ability or expertise cannot guarantee that one can develop his competence such as collaboration, leadership and good communication with others.

5) General

EQ competence is also a common competence that can be used in a variety of occupations 


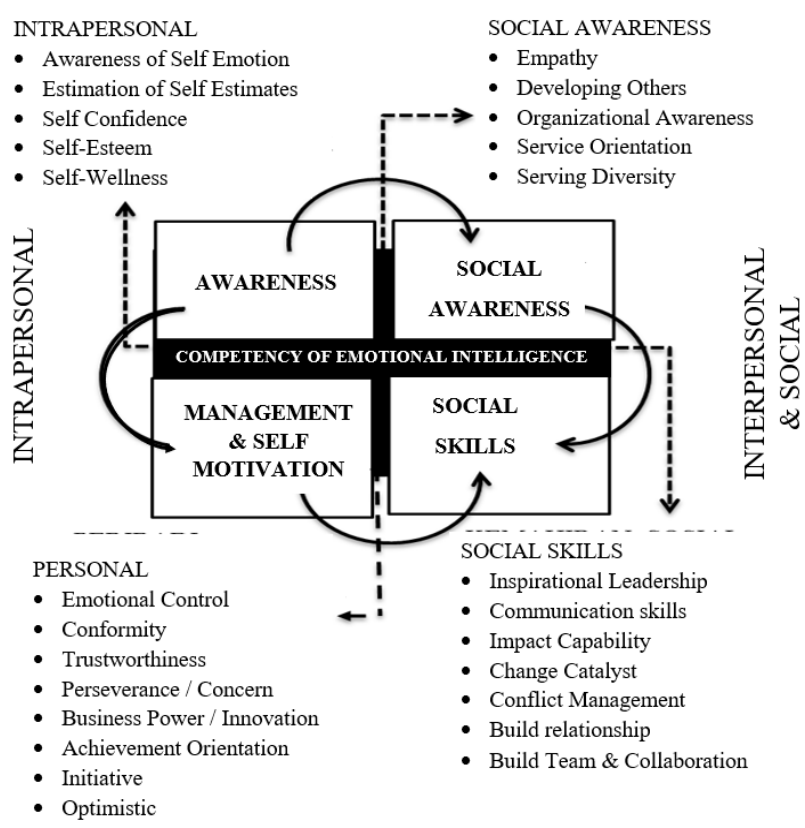

Fig. 4: Model of emotional intelligence of Goleman (1998) Source: Modified from Goleman (1998) "Working With Intelligence" New York, Bantam: m.s 32-34

\section{INTRAPERSONAL COMPONENTS OF SELF AWARENESS AND SELF-MANAGEMENT}

The determination of a person's way of managing the emotional self can be seen through personal competence that includes self-awareness, self-management and motivation.

\section{A. Self-Awareness}

1. Emotional awareness describes how an individual understands and recognises his or her emotions and implications.

2. Self-assessment describes how individuals understand their strengths and weaknesses.

3. Self-confidence explains how an individual has a strong sense of self-esteem and the skills possess.

\section{B. Self-Management / Self-Regulation}

1. Self-control explains how an individual controls the form of bad and negative emotions.

2. Trust explains how an individual maintains honesty and integrity.

3. Accuracy explains how an individual takes responsibility for his or her performance.

4. Adaptation explains how an individual can or is flexible in managing change.

5. Innovation explains how an individual feels comfortable with new ideas, approaches, and information.

\section{Motivation}

1. Achievement drive explains how an individual works towards improving excellence and self-achievement.

2. Commitment describes how an individual aligns ith the goals of the group or an organisation.

3. Optimists explain how an individual is consistent and determined in achieving the goal despite having to face various obstacles and obstacles.

\section{INTERPERSONAL COMPETENCE - SOCIAL AWARENESS AND SOCIAL SKILLS}

Social competence illustrates how an individual is trying to control relationships with others. This social competency includes empathy and social skills.

\section{A. Social Awareness}

1. Empathy: Understanding others explains how an individual can identify the feelings of others and care for them.

2. Forming others explains how an individual can identify the needs of others' self-development and highlight their ability.

3. Service orientation explains how an individual identifies, interprets and meets the needs of the customer.

4. Digestive diversity explains how an individual improves the opportunities available through various parties.

5. Political awareness explains how an individual understands the power relations with emotional waves.

6. The effect explains how an individual attempt to create an effective strategy for sequencing.

7. Communication explains how an individual is listening effectively and sending convincing messages.

8. Conflict management explains how individual negotiates and resolves disputes.

9. Leadership explains how an individual gives inspiration and guidance to other individuals and groups.

\section{B. Social Skills}

1. The change agency describes how an individual initiates or manages the change.

2. Building relationships explain how an individual is able to form an instrumental relationship.

3. Cooperation explains how an individual can work with other parties for common goals.

4. Group skills describe how an individual can create a group synergy in common goals.

\section{MEASUREMENT OF EMOTIONAL INTELLIGENCE}

A person's level of emotional intelligence can be assessed using emotional intelligence and self-report tests. Therefore, one cannot judge the best (or bad) answer for himself who differs from the actual situation.

The Bar-On Emotion Quotient Inventory (EQ-i) table (1997a, 1997b) encompasses both aspects of intrapersonal and interpersonal ideas in line with EQ Mayer \& Salovey, Mayer-Salovey-Caruso Emotional Intelligence Test (MSCEIT) (1997) EQ Goleman model, Emotional Competency Inventory (ECI) 
(1998). Although in terms of empirical studies, the constructs of constructing these models differ but empirically the research shows that the models have the same constructs in terms of their content and meanings (Conte, 2005).

Referring to Table 2 below, there are six types of emotional intelligence measuring devices from 60 types of emotional intelligence measures listed in "Measuring Emotional Intelligence and Related Constructs" (Schutte \& Malouff, 2001). The tools are really well-known as effective measuring tools, Mayer -Salovey-Caruso Emotional Intelligence Test (MSCEIT) (Mayer \& Salovey, 1997), Emotional Quotient Inventory (EQ-i) / Bar-On, Emotional Competency Inventory (ECI), Emotional Intelligence Appraisal (EIA) Intelligence Version (WPQei), Levels of Emotional Awareness Scale (LEAS) and Self-Report Emotional Intelligence Test (SREIT).

Table 2: Measurements for the Use of Emotional Intelligence

\begin{tabular}{|c|c|c|c|}
\hline Measure & $\begin{array}{l}\text { Correspondi } \\
\text { ng Theorist }\end{array}$ & $\begin{array}{l}\text { Mode of } \\
\text { Measure }\end{array}$ & $\begin{array}{c}\text { Brief } \\
\text { Description }\end{array}$ \\
\hline $\begin{array}{l}\text { Mayer-Salove } \\
\text { y-Caruso } \\
\text { Emotional } \\
\text { Intelligence } \\
\text { Test } \\
\text { (MSCEIT) } \\
\text { Mayer and }\end{array}$ & $\begin{array}{l}\text { Mayor and } \\
\text { Salovey } \\
(1997)\end{array}$ & $\begin{array}{l}\text { Based on } \\
\text { Potential } \\
\text { Performan } \\
\text { ce }\end{array}$ & $\begin{array}{l}\text { Specific tasks are } \\
\text { used to measure } \\
\text { the level of ability } \\
\text { of each branch of } \\
\text { emotional } \\
\text { intelligence. }\end{array}$ \\
\hline
\end{tabular}

$\begin{array}{ll}\text { Emotional } & \\ \text { Quotient } & \text { Bar-On } \\ \text { Inventory } & \text { (1997) } \\ \text { (EQ-i) } & \end{array}$

\section{Self-report} items measure the amount of IQ and Self-report EQ on each of the 5 Bar-On model components

Various measuring

Emotional Competency Inventory Goleman (ECI) (1999) / (1998) (ESCI) (2007)

Emotional Intelligence Appraisal Goleman (EIA)

\section{EQ-Map}

Levels of

$\begin{array}{ll}\text { Emotional } & \text { Cooper } \\ \text { Awareness } & \text { Other } \\ \text { Scale (LEAS) } & \end{array}$

$\begin{array}{ll}\text { Emotional } & \text { Cooper } \\ \text { Awareness } & \text { Other }\end{array}$

Scale (LEAS)

Self-Report

\begin{tabular}{|c|c|}
\hline Emotional & Mayer \\
\hline Test (SREIT) & Other \\
\hline
\end{tabular}

Test (SREIT) Other

33-item concepts from Salovey and Mayer's emotional intelligence

\section{A. Multi-Factor Emotional Intelligence Scale (MEIS) or Mayer, Salovey \& Caruso Emotional Intelligence Test (MSCEIT)}

The Multi-factor Emotional Intelligence Scale (MEIS); consists of several series of assignments to assess the ability of the participants to see, impress, know for sure, understand and take care of emotions.

Referring to Figure 5, the first component is the perception of emotions which involves the ability to perceive, assess and express emotions. The characteristics are:

1. Discriminating emotions between honest and betrayal

2. Express expressions correctly

3. Get to know the emotions of others

4. Knowing emotions in yourself

The second component is the use of emotions related to utilizing and facilitating thinking with emotions. The characteristics are:

1. Using the emotional state to make it easier to solve problems and creativity

2. Utilising emotions in terms of a choice perspective

3. Utilising emotions in facilitating consideration

The third component is understanding emotions that involve knowledge of emotions that are the same or that are intermittent or that are related to understanding emotions and practising emotional knowledge. The characteristics are:

1. Understanding the transition between emotions

2. Explaining complex emotions

3. Understand how the links of different emotions relate to one another.

4. Practice emotions in solving problems

The fourth component is managing emotions that involves understanding the implications of social actions for emotions and controlling emotions in oneself and others.emotions in oneself and others.

\section{B. Bar-On / EQ-I Inventory (Bar-On Emotional Quotient Inventory (EQ-i)}

The Emotional Quotient Inventory (EQ-i) Bar-On is a measurement tool $\mathrm{i}-\mathrm{n}$ the form of the longest formed report, since the past two decades. So far the EQ-i instrument is the most complete tool for measuring emotional intelligence. 


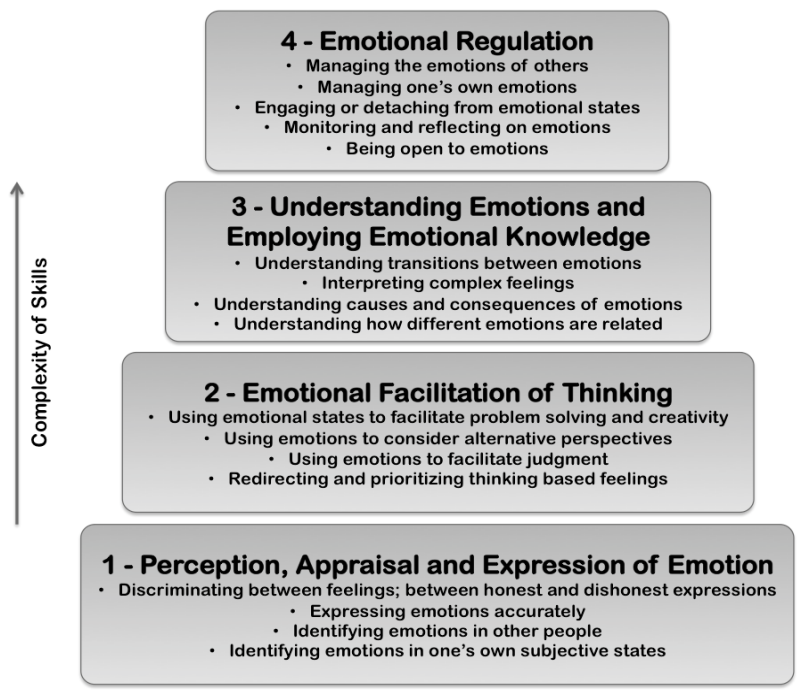

Fig. 5: Source: Emotional Intelligence and Project Leadership an Explorative Study Master of Science Thesis in the Master's Programme International Project Management Joni Christian Vierimaa

EQ-i is a vehicle report instrument starting from the clinical context so that it can be used to develop skills and connection in employment. This inventory can measure the strength of emotional intelligence, the potential for emotional health and well-being in terms of psychology.

This section measures the ability of a person to adjust his or her feelings, thoughts and behaviours with changes in circumstances and situations and measure the ability to manage the changes experienced.

The fifth part is the heart that includes an optimistic and cheerful attitude that gauges one's ability to self-propagate towards the aim.

\section{ECI Emotional Competence Inventory (ECI) Competency Inventory}

This instrument is designed by Richard Boyatzis and Daniel Goleman (1998). Emotional intelligence is a set of skills that can be measured through the use of its inventor called the Emotional Competency Inventory (ECI). ECI is an emotional intelligence measuring instrument that provides 360-degree feedback. According to Goleman, (1998) through ability to identify himself or others with emotional intelligence. The study indicated that the scores obtained from these inventory measurements can give an early perception and overview at the credibility of a person, especially at the workplace as reported by 360-degree feedback.

This instrument provides information about one's emotional intelligence at work is a tool for self-development and self-improvement of workers and not as a tool that provides information on decision related to hiring or for informational reasonableness of paying remuneration to workers.

ECI measures four aspects of emotional intelligence. Fourth, social skills covering inspired leadership, communication skills, influencing capabilities, catalytic change, conflict management, building relationships, the 20 skills tested by a person; on whether he/she has the

collaboration and team building.

\section{EMOTIONAL INTELLIGENCE MAPPING (EQ-MAP)}

Another set of emotional intelligence is the scale of the EQ-Map self-report (Cooper, 1997) parallel to EQ-i. The second attribute is a literacy that measures self-emotional awareness, emotional discharge and emotional awareness of others. Finally, the revenue resulted clear outcomes of emotional intelligence, such as general health, quality of life, optimal intelligence and achievement.

\section{THE IMPORTANCE OF EMOTIONAL INTELLIGENCE TO ENTREPRENEURS}

Innovation and creativity in entrepreneurship are contributing towards organisational change and development towards the achievement of the post Vision 2020. The effort to cultivate creative and innovative thinking among entrepreneurs and potential entrepreneurs is based on the Plan of Education Development Master Plan (PIPP 2006-2010) and (PIPP 2013-2018) capitalises on human and soft skills with emotional intelligence as the core of positive attitude. This attitude needs to be nurtured from school.

The concept of entrepreneurial culture based on creativity and innovation is justified in harmony between soft skills and emotional intelligence. In many EQ studies among successful entrepreneurs, EQ elements have taken creative and innovative action to identify themselves, improve themselves, wisely establish bilateral ties in organisational communication, enhance the creativity and creativity knowledge as k-worker, raise the level of integration of e-learning \& e-teaching in entrepreneurship, awakening power of imagination, the courage to change to the risk of taking self-reliance on his God and improving the competence of emotional intelligence (KKE) and the culture of a steady entrepreneur as an innovation (R. Mohd Rosli, 2013).

The ingenuity of using emotional intelligence will give entrepreneurs an edge especially in enhancing the integrity of entrepreneurial entrepreneurship such as creativity, innovation, proactive and risk-taking. Thus, successful entrepreneurs in the workplace need to have tremendous emotional intelligence.

\section{REFERENCES:}

[1] Bar-On, R.A. $\left(1997^{\mathrm{a}}\right)$, Bar On Emotional Quotient Inventory, A Measure of Emotional Intelligence, Multi-Health Systems Inc, Toronto, ON-North Tonawanda, NY, pp 1-19

[2] Bar-On, R.A. $\left(1997^{\mathrm{b}}\right)$. The emotional quotient inventory (EQ-I): Technical manual. Toronto, Canada: Multi-Health Systems.

[3] Bar-on, R.A. (2000). "Psychological Perspectives on Entrepreneurship: Cognitive and Social Factors in Entrepreneurs Success." Current Directions in Psychological Science 9(1): 15-18.

[4] Bloom, B.S. (Ed.). Engelhart, M.D., Furst, E.J., Hill, W.H., Krathwohl, D.R. (1956). Taxonomy of Educational Objectives, Handbook I: The Cognitive Domain. New York: David McKay Co Inc.

[5] Conte, J. M. (2005). A review and critique of emotional intelligence measures. Journal of Organizational Behavior, 26(4), 433-440.

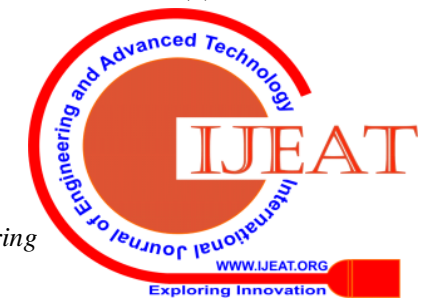


[6] Cooper, R.K. and Sawaf, A. (1997). Executive EQ: Emotional Intelligence in Leadership and Organizations. Berkeley. New York, NY.

[7] Derksen, J., Kramer, I., \& Katzko, M. (2002). Does a self-report measure for emotional intelligence assess something different than general intelligence? Personality and Individual Differences, 32, 37-48.

[8] Goleman, D. (1995). Emotional Intelligence: Why It Can Matter More Than IQ. New York: Bantam Book.

[9] Goleman, D. (1998). 'Working with emotional intelligence'. New York: Bantam Books

[10] Goleman, D. (1999). An EI-Based Theory of Performance From the book The Emotionally Intelligent Workplace Edited by: Cary Cherniss and Daniel Goleman. Consortium for Research on Emotional Intelligence in Organizations. EI and Performance, pp. 1-18 (www.eiconsortium.org )

[11] Goleman, D., Boyatzis, R., \& McKee, A. (2001). Primal leadership: The hidden driver of great performance. Harvard business review, 79(11), $42-53$.

[12] Mayer, J.D. \& Salovey, P, (1990). Emotional intelligence. Imagination, cognition, and personality, 9(3), 185-211.

[13] Mayer, J. D., \& Salovey, P. (1993). The intelligence of emotional intelligence Vol. 17, pp. 433-442

[14] Thorndike, E.L. (1920). Intelligence and its use. Harper's Magazine, 140, 227-235.

[15] Mayer, J.D., \& Salovey (1997). Educational Development and Emotional Intellgence. New York: Basic Books, pp.185-211

[16] Mayer, J. D., Roberts, R. D., \& Barsade, S. G. (2008). Human abilities: Emotional intelligence. Annu. Rev. Psychol., 59, 507-536.

[17] Murray, H.A. (1998). Explorations in personality. New York: Oxford University press

[18] Newman, Daniel A. and Joseph Dana L. (2010). Emotional Intelligence: An Integrative Meta-Analysis and Cascading Model Journal of Applied Psychology @ 2010 American Psychological Association 2010, Vol. 95, No. $1,54-78$

[19] R. Mohamad Zulkifli dan M. Mohd Rosli (2013). Entrepreneurial Orientation and Business Success of Malay Entrepreneurs: Religiosity as Moderator. International Journal of Humanities and Social Science Vol. 3 No. 10 [Special Issue - May 2013]

[20] Schutte, N.S., E. Schuettpelz, and J.M. Malouff. 2001. "Emotional Intelligence and Task Performance." Imagination, Cognition and Personality 20(4): 347-354.

[21] Yitshaki, Ronit, (2012). How do entrepreneurs' emotional intelligence and transformational leadership orientation impact new ventures' growth Journal of Small Business and Entrepreneurship Publisher: Canadian Council for Small Business and Entrepreneurship. Summer,2012 Source Issue: 3

[22] Yvonne Stys \& Shelley L. Brown (2004) . A Review of the Emotional Intelligence Literature and Implications for Corrections. Research Report. Research Branch Correctional Service of Canada

\section{AUTHOR's ProfiLES}

Jimisiah Jaafar, Universiti Kuala Lumpur, Malaysia. The Area of Exerttise is Entrepreneurship, Emotional Intelligence.

Halimah Mohd Yusof, Universiti Teklonogi Malaysia. Research Areas are Human Behaviour and psychology

Sallaudin Hassan, Universiti Kuala Lumpur, Malaysia. Expertise in Strategic Managemnt and Project Mangement.

Khairul Firdaus Adtrudin, Universiti Kuala Lumpur, Malaysia.

Rohaizan Ahmad, Universiti Kuala Lumpur, Malaysia. 